\title{
Experiencias sobre Anestesia por infiltración en el Raspado Uterino
}

\author{
Dr. Santiago Pérez Ariza \\ Del Instituto Materno Infantil - Bogotá
}

Ante la cantidad verdaderamente grande de casos de aborto que se presentan en el Instituto Materno Infantil, en mi doble carácter de anestesiólogo y obstetra, pensé en la posibilidad de mover el servicio más rápido, sin abandonar mi responsabilidad obstétrica, colaborando con el Departamento de Anestesiología; es así como decidí aplicar anestesia local para llevar a cabo los raspados uterinos.

No se hizo en el curso de este trabajo ninguna clasificación de la paciente con respecto al tipo de raspado, ni a condiciones físicas generales, sino que se tuvieron en cuenta solamente detalles de carácter técnico.

Como siempre que se va a aplicar un anestésico local deben tomarse medidas de precaución, consistentes en encontrar la idiosincrasia del paciente por la droga, así se hizo en este trabajo y las pruebas consistieron en control de tensión arterial, pulso y respiraciones, así como el estado de las conjuntivas de la paciente a anestesiar. Las pruebas de sensibilidad consistieron en aplicar en la conjuntiva una gota del anestésico, ya que en este sitio la absorción de la droga, debido a la irrigación muy pobre de la conjuntiva es muy lenta y no alcanza a producir ninguna reacción desagradable, y no aplicándola subcutáneamente pues las reacciones no se deben al volumen de la substancia sino a ella en sí, y puede ser fatal tanto una décima como un centímetro cúbico de la misma.

Diez minutos después de aplicada la gota en el ojo, se controlan nuevamente la tensión arterial, el pulso y las respiraciones 
por minuto así como se vuelve a examinar la conjuntiva; si no ha habido variaciones notorias en la tensión, o el pulso y las respiraciones no han aumentado en un número mayor de diez, la paciente es apta para aplicarle el anestésico local. Estas reacciones de idiosincrasia son de tipo histamínico, consistentes en molestias oculares, fotofobia hiperhemia reacciones de tipo cortical consistentes en convulsiones, tics, ya sea en los dedos, párpados, o músculos frontales; y por último reacciones anafilácticas que se manifiestan por taquifilaxia.

Si en el caso concreto no aparecen reacciones histaminoidea, cortical o anafiláctica con un aumento del pulso o las respiraciones por encima de diez puede aplicarse el anestésico; de lo contrario es necesario abstenerse pues pueden presentarse reacciones de intolerancia e inclusive la muerte.

\section{ANESTESICO A USAR}

En este trabajo solo se usó como anestésico la Dietil-Amina 2, 6-Dimetil Acetanilida,* y erı su forma de presentación simple, es decir, sin epinefrina.

La Xilocaína como todo buen anestésico local, es de acción rápida, además es completa y prolongada como lo demuestra uno de los casos en el cual el raspado se extendió por espacio de cuarenta minutos. Tiene un poder de difusión muy grande y da un amplio margen de seguridad.

\section{TECNICA ANESTESICA}

Una vez hechas las pruebas de sensibilidad, es necesario aplicar una medicación pre anestésica. Inicialmente consistió en aplicar Fenergán I. M.; posteriormente se le agregó Gardenal, y luego, esperando por espacio de cuarenta y cinco minutos se procedió a aplicar el anestésico, estando la paciente en posición ginecológica.

Elementos necesarios. - Una valva de peso o en su defecto un espéculum, una pinza de Allis, una jeringa de 20 c.c., una aguja calibre 22 de dos pulgadas.

* Xylocaína ASTRA. 
Se comienza anestesiando subcutáneamente la horquilla vulvar con un centímetro cúbico, se coloca el espéculum o la valva de peso, personalmente prefiero la valva, se pinza el cuello del útero y en el sitio de la reflexión de la mucosa vaginal sobre el cuello se inyecta el anestésico en los sitios comparados con el reloj $12,6,9,3$. Se considera buena la infiltración, cuando el cuello adquiere una zona blanquecina de isquemia; el punto de la horquilla tiene por objeto, que la molestia de la valva sea ínfima.

\section{Cantidad y concentración del anestésico utilizado}

Inicialmente se utilizó Xilocaína al i\% en la cantidad de 15 a 20 c.c. repartidos en iguales partes en cada uno de los sitios indicados antes; se llegó a la conclusión luego de 17 casos, de que el anestésico era insuficiente, se utilizó entonces la concentración del $2 \%$ por dos ocasiones con resultados idénticos; vino entonces el dilema de si aplicar mayor volumen anestésico o cambiar la concentración del mismo. utilicé entonces la concentración al $0.75 \%$ diluyéndolo en agua destilada o solución salina fisiológica hasta un volumen de 40 c.c. y los resultados fueron cada vez más satisfactorios, debido a que en anestesia de infiltración, da mejor resultado el volumen inyectado y no la concentración del anestésico, se utilizó entonces diluído en agua buscando volumen para evitar esfacelos y ulceraciones del cuello.

En esta forma quedan anestesiados los ramos sensitivos que el ganglio de Frankenhausen y el ganglio mesentérico inferior mandan al útero. Ya en este estado de cosas, puede procederse a efectuar el raspado uterino ya sea por aborto incompleto o para diagnóstico ginecológico con dilatación del cuello.

\section{RESULTADOS OBTENIDOS}

A medida que la técnica anestésica se fue perfeccionando, los resultados fueron cada vez mejores; los primeros casos fueron aceptables pero no indoloros; con la concentración al 1\%, hubo dolor al pasar la cureta o hacer escobillonaje, pero era un dolor muy soportable. Con esta concentración considero un caso de verdadero fracaso. Al cambiar la dilución y hacer mejor la 
infiltración, los resultados llegaron a ser perfectamente indoloros.

\section{RESPUESTAS DE LAS PACIENTES}

A pesar de las precauciones tomadas, algunas pacientes dieron para la Xilocaína ligeras intolerancias, como zumbidos de oîdos, cefálea, visión borrosa, escalofríos y midriasis, todas de forma muy benigna y que se recuperaron muy pronto con solo aplicar oxígeno.

Hubo un caso severo (historia 77861) en el que una vez terminado el raspado uterino, que duró por espacio de 10 minutos y que fué perfectamente indoloro, se aplicó como de rutina una ampolla de ergotrate I. M. La paciente empezó a presentar gran cefálea, visión borrosa y disnea, y al controlar la tensión arterial se le encontró 130 × 100 cuando inicialmente tenía 100 x 60 y aumento del pulso de 70 inicialmente a 80 ; auscultado el corazón se apreciaron los ruidos normales, bien timbrados, luego se observaron movimientos convulsivos de los dedos de las manos, y tics de los músculos de la frente, pérdida de la noción del espacio, para continuar luego con trismus de los maseteros e inminencia de ahogo.

Se observa en esta paciente una reacción tardía de tipo cortical y de taquifilaxia; como tratamiento se le aplicó en primer lugar oxígeno, y luego Cafeína I. M.; los síntomas fueron regresando rápidamente y lo último en recuperarse fue la noción del espacio. Interrogada la paciente dijo no acordarse de nada y solamente sentir sensación de cansancio y sefalea. Quedó en observación por espacio de cuatro días, al cabo de los cuales se marchó del Instituto en buenas condiciones.

La explicación del caso es a mi juicio la siguiente: la absorción de la Xilocaína fue lenta e hizo un ligero edema cerebral. Se cometió un error en el tratamiento del accidente y fue la aplicación de la Cafeína, estimulante de la corteza, que estaba ya excitada por la Xilocaína. El tratamiento indicado hubiera sido un barbitúrico I. V. 
Vol. XII

\begin{tabular}{|c|c|}
\hline No. Casos & $\begin{array}{c}\text { Con } \\
\text { D i I a tación }\end{array}$ \\
\hline $70-(100 \%$ & D ilatación \\
\hline $12-(17.14 \%)$ & $58-(82.85 \%)$ \\
\hline
\end{tabular}

CONCENTRACION VOLUMEN y RESULTADO ANESTESICO

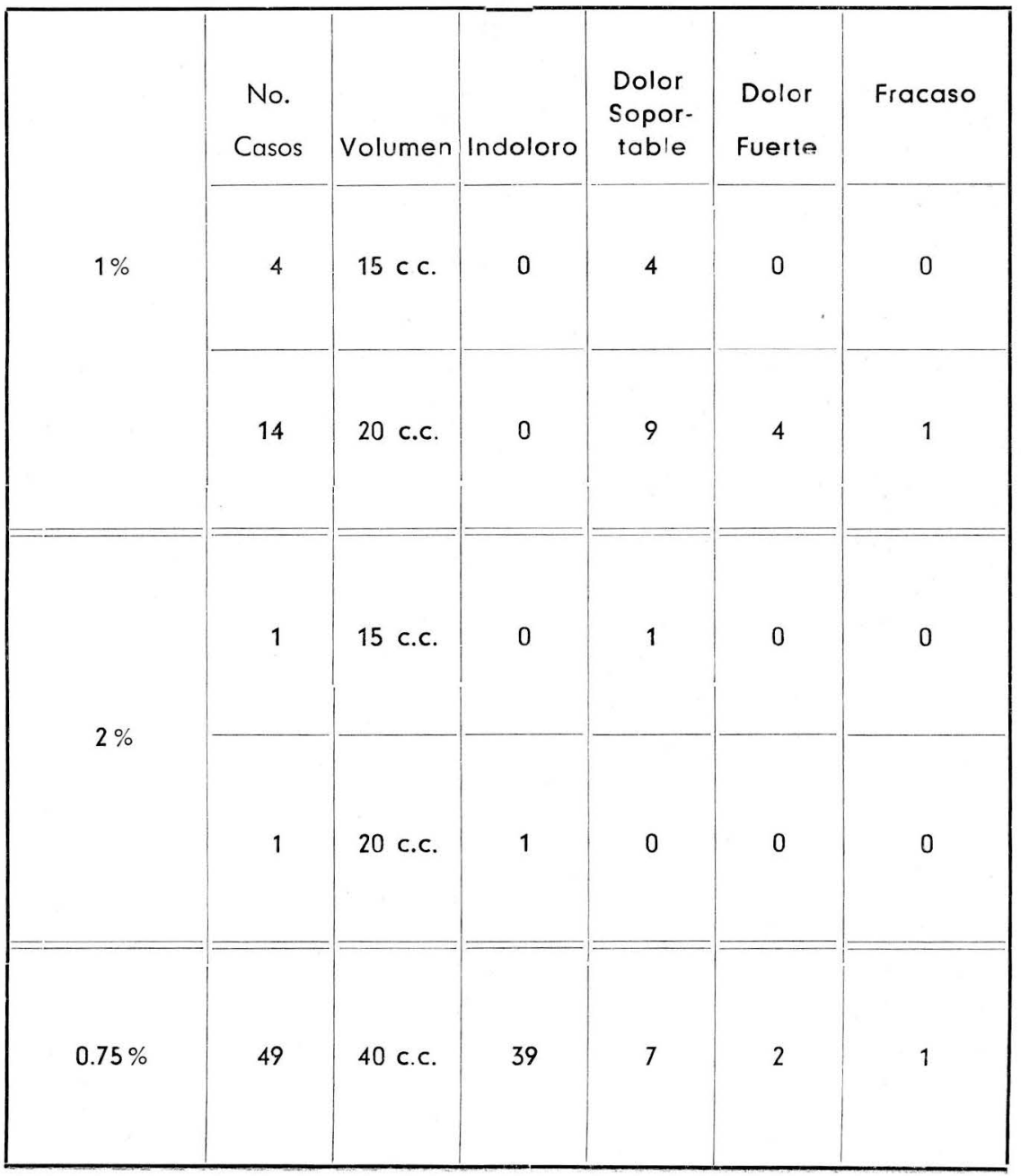




\section{CONCLUSIONES}

Se puede efectivamente practicar raspado uterino a una paciente en forma indolora con anestesia local por Infiltración. Para ello es absolutamente necesario adiestrarse en la técnica anestésica. La Xilocaína como anestésico local da un amplio margen de seguridad, siempre y cuando se tomen las medidas de precaución indispensables. En el curso de este trabajo se encontraron solamente tres casos de reacción sin ninguna importancia que cedieron fácilmente a la aplicación de oxígeno y un caso severo que fue analizado anteriormente. Cuatro pacientes fueron excluídas de este estudio por no considerarlas aptas para el tipo de anestesia usada.

En las pacientes en estado de pre shock o en franco shock, en las que debido a su mal estado no se puede aplicar una anestesia general o raquídea, la anestesia regional por infiltración es la ideal.

L. TESTUT. Tomo 41934.

\section{BIBLIOGRAFIA}

NOVAK y NOVAK. pág. 18. Tratado de Ginecología.

HINGSON and HELLMAN. Anesthesia for Obstetrics.

EASTMAN. Obstetricia de Williams.

DE LEE-GREENHILL. Principios y práctica de Obstetricia. Tomo I. 